\title{
Polysaccharide peptide isolated from grass-cultured Ganoderma lucidum induces anti-proliferative and pro-apoptotic effects in the human U251 glioma cell line
}

\author{
CHUNHUA WANG ${ }^{1,2}$, DONGMEI LIN ${ }^{3}$, QUAN CHEN ${ }^{1}$, \\ SHUQIAN LIN ${ }^{3,4}$, SONGSHENG SHI ${ }^{1,2}$ and CHUNMEI CHEN ${ }^{1,2}$
}

\begin{abstract}
${ }^{1}$ Department of Neurosurgery, The Affiliated Union Hospital of Fujian Medical University; ${ }^{2}$ Fujian Neurosurgical Institute, Fuzhou, Fujian 350001; ${ }^{3}$ National Engineering Research Center of JUNCAO Technology, Fujian Agricultural and Forestry University; ${ }^{4}$ Fuzhou Institute of Green Valley Bio-Pharm Technology, Fuzhou, Fujian 350002, P.R. China
\end{abstract}

Received July 18, 2016; Accepted November 21, 2017

DOI: $10.3892 / \mathrm{ol} .2018 .7823$

\begin{abstract}
The Ganoderma lucidum (G. lucidum) mushroom is one of the most extensively studied functional foods, known for its numerous health benefits, including the inhibition of tumor cell growth. The present study assessed the anti-proliferative and pro-apoptotic activity of a novel G. lucidum polysaccharide peptide (GL-PP) in human glioma U251 cells, which was purified from grass-cultured G. lucidum. GL-PP is a glycopeptide with an average molecular weight of 42,635 Da and a polysaccharide-to-peptide ratio of 88.70:11.30. The polysaccharides were composed of 1-arabinose, d-mannose and d-glucose at a molar ratio of 1.329:0.372:2.953 and a total of 17 amino acids were detected. The results of the current study demonstrated that GL-PP significantly inhibited U251 cellular proliferation. The proportion of $G_{0} / G_{1}$ phase cells and sub- $G_{1}$ phase cells significantly increased as the concentration of GL-PP increased, as did the activity of caspase-3. These results indicate that GL-PP directly inhibited human glioma U251 proliferation by inducing cell cycle arrest and promoting apoptosis.
\end{abstract}

\section{Introduction}

Malignant gliomas are the most common type of brain tumor, with high rates of recurrence and mortality (1). Despite the aggressive use of surgery, radiotherapy and chemotherapy, the average life expectancy of patients with high-grade glioma is 14 months after diagnosis (2). Novel treatments

Correspondence to: Dr Chunmei Chen, Department of Neurosurgery, The Affiliated Union Hospital of Fujian Medical University, 29 Xinquan Road, Fuzhou, Fujian 350001, P.R. China

E-mail: chenchm_mail@126.com

Key words: Ganoderma lucidum, polysaccharide peptide, glioma, anti-proliferation, apoptosis are therefore required to improve this figure. In recent years, natural products isolated from herbs and plants have received substantial attention for their potential as novel anticancer drugs (3).

Ganoderma lucidum is a mushroom that has been used for medicinal purposes for centuries in China and other oriental countries. G. lucidum polysaccharides (GL-PS) are primary bioactive components of the fungus that can exert various pharmacological effects, including immunomodulation (4-10), antitumor (11-16), anti-angiogenesis $(17,18)$, anti-oxidation (19-22), anti-inflammatory (23) and hepatoprotective effects $(24,25)$.

The potential antitumor effects of GL-PS have received substantial attention and have been the subject of extensive investigation. It has been demonstrated that GL-PS is effective at inhibiting tumor growth in vivo via multiple mechanisms, particularly via the activation of immune effector cells such as lymphocytes (9,26-29), macrophages (9) and natural killer cells $(29,30)$. GL-PS has also been revealed to inhibit tumor-induced neovascularization processes. However, GL-PS is considered to possess weak or no antitumor activity in vitro $(17,28,31-34)$. Previous studies have demonstrated that GL-PS may directly inhibit the in vitro proliferation of certain types of cancer cell, including breast cancer (14), ovarian cancer (15), colorectal cancer (23) and hepatoma cells (11). However, whether GL-PS elicits antitumor effects on gliomas remains unknown. In the present study, we isolated and identified a 42,635 Da G. lucidum polysaccharide peptide (GL-PP) from G. lucidum cultivated with JUNCAO grasses and determine its antitumor effects on gliomas for the first time. It was revealed that this GL-PP exhibited anti-proliferative and apoptosis-inducing effects in human U251 glioma cells.

\section{Materials and methods}

Preparation of GL-PP. GL-PP was isolated from the boiled extract of G. lucidum cultivated with JUNCAO grasses (National Engineering Research Center of Juncao Technology, Fujian, China). An ethanol precipitation was then performed, 
followed by dialysis and de-proteination according to the Sevag method, as previously described (35).

The homogeneity and molecular weight of GL-PP was identified using high-performance gel permeation chromatography (HPGPC) with a Waters 2695 HPLC apparatus (Waters, Milford, MA, USA), equipped with a Waters 2515 HPLC pump (Waters), a gel permeation column TSK4000PW (21.5x300 mm, $10 \mu \mathrm{m}$; Tosoh, Tokyo, Japan) and a Waters 2414 refractive index detector (Waters). Water (HPLC grade) was used as the mobile phase with a gradient elution (flow rate of $0.8 \mathrm{ml} / \mathrm{min}$ ) at $35^{\circ} \mathrm{C}$. Dextran standards were obtained from the National Institutes for Food and Drug Control and molecular weights ranging from 2,500 to 84,400 Da were used to generate a calibration curve (36). The molecular weight of GL-PP was estimated using Waters Empower software (version 5.0; Waters).

Monosaccharides were determined using hydrophilic interaction liquid interface chromatography and an evaporative light scattering detector (HILIC-ELSD) via a Waters Alliance 2695 HPLC system and 2424 ELSD (both from Waters). Chromatographic separation was performed on a Sugar-D column $(4.6 \times 250 \mathrm{~mm} ; 5 \mu \mathrm{m}$; Nacalai Tesque, Inc., Kyoto, Japan). The column was run at $35^{\circ} \mathrm{C}$ and the mobile phase consisted of $75 \%$ acetonitrile and $25 \%$ water, at a flow rate of $0.8 \mathrm{ml} / \mathrm{min}$. The drift tube temperature and air carrier gas pressure of the ELSD was set to $55^{\circ} \mathrm{C}$ and 45 psi, respectively. The injection volume was $10 \mu l$. The identity of sample monosaccharides were determined by comparing the retention time of peaks with those of known standards including, rhamnose, fructose, xylose, arabinose, glucose, galactose and mannose.

The amino acid composition of GL-PP was determined using the Hitachi-L8800 amino acid analyzer (Hitachi High-Technologies Co., Tokyo, Japan) according to the Chinese National Standard (37).

GL-PP was dissolved in serum-free Dulbecco's modified Eagle's medium (DMEM; HyClone; GE Healthcare Life Sciences, Chicago, IL, USA), then filtered through a $0.22-\mu \mathrm{m}$ filter and stored at $4^{\circ} \mathrm{C}$. This medium was further diluted to the indicated concentration prior to each assay.

Endotoxin test. The presence of an endotoxin in GL-PP was detected using Tachypleus Amebocyte Lysate (TAL; Fuzhou Xin Bei Biochemical Industry Co., Ltd., Fuzhou, China) according to the manufacturer's instructions. A total of $100 \mu \mathrm{l}$ TAL reagent was added to $100 \mu \mathrm{l}$ of $800 \mu \mathrm{g} / \mathrm{ml}$ GL-PP, $100 \mu \mathrm{l}$ endotoxin standard (Fuzhou Xin Bei Biochemical Industry Co., Ltd.) and $100 \mu 1$ endotoxin-free water. The mixture was gently agitated, covered with foil and incubated at $37^{\circ} \mathrm{C}$ for $1 \mathrm{~h}$. Since endotoxin contamination results in the formation of a hard gel substance, samples were observed for the formation of this gel by performing a gentle $180^{\circ}$ tube inversion following the incubation period.

Cell culture. The human glioma U251 cell line was obtained from the Type Culture Collection of the Chinese Academy of Sciences (Shanghai, China) where it was routinely maintained in DMEM containing 10\% inactivated fetal bovine serum (FBS; HyClone; GE Healthcare Life Sciences) and $100 \mathrm{U} / \mathrm{ml}$ penicillin/streptomycin. Cells were grown at $37^{\circ} \mathrm{C}$ in an atmosphere of $5 \% \mathrm{CO}_{2}$.
Cell proliferation assay. Cell proliferation and viability were analyzed using the Cell Counting Kit-8 (CCK-8; Dojindo Molecular Technologies, Inc., Kumamoto, Japan). U251 cells were seeded onto 96-well culture plates at a density of 2,000 cells/well and cultured for $24 \mathrm{~h}$ prior to treatment. GL-PP was added to the culture at a final concentration of 50,100, 200,400 or $800 \mu \mathrm{g} / \mathrm{ml}$ and cells were incubated for a further 24,48 or $72 \mathrm{~h}$. Wells that were not treated with GL-PP were used as negative controls. The CCK- 8 reagent was then added to the cultures according to manufacturer's instructions and absorbance was measured at $450 \mathrm{~nm}$ using an ELISA MK3 microplate reader (Thermo Fisher Scientific Inc., Waltham, MA, USA). All measurements were performed in triplicate.

Cell cycle assay. $\mathrm{U} 251$ cells $\left(2.5 \times 10^{4}\right.$ cells $\left./ \mathrm{ml}\right)$ were plated onto a 6 -well plate and harvested at $48 \mathrm{~h}$ following treatment. Cells were fixed in $70 \%$ ice-cold ethanol, washed with ice cold PBS and stained with $50 \mathrm{mg} / \mathrm{ml}$ propidium iodide in the presence of $50 \mathrm{mg} / \mathrm{ml} \mathrm{RNase} \mathrm{A} \mathrm{for} 30 \mathrm{~min}$. Staining procedures were performed under low light at room temperature. Analyses were performed using a flow cytometer (Cytomics FC 500; Beckman Coulter Inc., Brea, CA, USA). Cell proportions in sub- $\mathrm{G}_{1}, \mathrm{G}_{0} / \mathrm{G}_{1}, \mathrm{~S}$ and $\mathrm{G}_{2} / \mathrm{M}$ phases were analyzed using ModFit LT software (version 2.0; Verity Software House, Topsham, ME, USA). Tests were performed in triplicate for each sample.

Western blotting. A 6-well cell culture plate was prepared as aforementioned. Total protein was purified from cells using a cell lysis buffer (Beyotime Institute of Biotechnology, Haimen, China) containing $1 \mathrm{mM}$ phenylmethylsulfonyl fluoride. Protein concentrations were subsequently measured using a BCA kit (Beyotime Institute of Biotechnology) according to the manufacturer's instructions. Samples $(150 \mu \mathrm{g}$ protein/lane) were then separated on $12 \%$ SDS-PAGE gel and transferred onto a nitrocellulose membrane. $\beta$-actin (Cell Signaling Technology Inc., Danvers, MA, USA) was used as a loading control. The membrane was blocked with $5 \%$ bovine serum albumin (Sangon Biotech, Shanghai, China) at room temperature for $2 \mathrm{~h}$ and incubated overnight at $4^{\circ} \mathrm{C}$ with a rabbit polyclonal anti-active caspase- 3 antibody (1:1,000, cat. no. ab2302; Abcam, Cambridge, UK). The membrane was then incubated with a horseradish peroxidase conjugated goat anti-rabbit immunoglobulin G (1:2,000, cat. no. sc-2004; Santa Cruz Biotechnology Inc., Dallas, TX, USA) at room temperature for $2 \mathrm{~h}$. Protein expression was detected using a Chemiluminescent HRP Substrate (EMD Millipore, Billerica, MA, USA) and exposed on X-ray film. The optical density of each band was determined using Quantity One software (version 4.6.1; Bio-Rad Laboratories Inc., Hercules, CA, USA). The expression of cleaved caspase- 3 was expressed as a ratio to $\beta$-actin used as an internal control. Tests were performed in triplicate for each sample.

Caspase-3 activity assay. The activity of caspase-3 was determined using a Caspase 3 Activity Assay kit (Beyotime Institute of Biotechnology). To evaluate the activity of caspase-3, cell lysates were prepared following cell treatment with GL-PP for 48 h. Each $10 \mu \mathrm{l}$ cell lysate was incubated with $80 \mu \mathrm{l}$ reaction buffer [1\% NP-40, $20 \mathrm{mmol} / \mathrm{l}$ Tris- $\mathrm{HCl}(\mathrm{pH} 7.5)$, $137 \mathrm{mmol} / \mathrm{l} \mathrm{NaCl}, 10 \%$ glycerol] containing $10 \mu \mathrm{l}$ caspase-3 


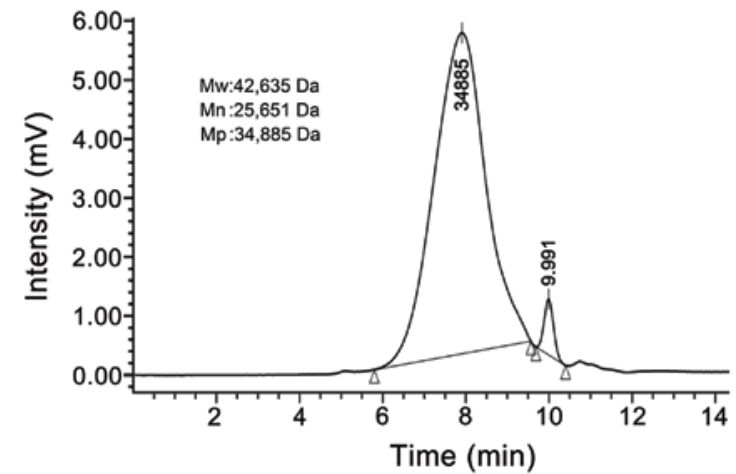

Figure 1. Typical gel-permeation chromatogram of GL-PP samples. Chromatograms of the average molecular weight and homogeneity of GL-PP as determined by high-performance gel permeation chromatography (Mw: mean molecular weight; Mn: Number-average molecular weight; Mp: Peak molecular weight) GL-PP, Ganoderma lucidum polysaccharide peptide.

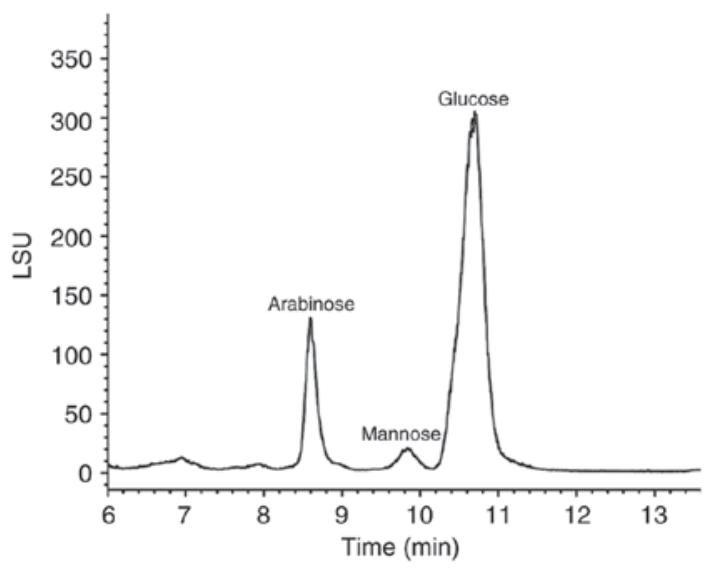

Figure 2. Identification and determination of major monosaccharides in the Ganoderma lucidum polysaccharide peptide using hydrophilic interaction liquid interface chromatography and evaporative light scattering detector analysis. LSU, light scattering unit.

substrate [2 mmol/1 acetyl-Asp-Glu-Val-Asp p-nitroanilide (Ac-DEVD-pNA)] at $37^{\circ} \mathrm{C}$ for $2 \mathrm{~h}$. Caspase-3 can catalyze the substrate Ac-DEVD-pNA to produce pNA. Thereafter, absorbance of pNA at $405 \mathrm{~nm}$ was measured using an ELISA plate reader (MK3; Thermo Fisher Scientific Inc.). The analysis procedure followed the manufacturer's instructions. All experiments were performed in triplicate.

Statistical analysis. The data were expressed as mean \pm standard deviation. Multigroup comparisons of the means were carried out by one-way analysis of variance test with post hoc Student-Newman-Keuls test. $\mathrm{P}<0.05$ was considered to indicate a statistically significant difference.

\section{Results}

Characterization of GL-PP. GL-PP was determined to be a polysaccharide peptide with a mean molecular weight (Mw) of 42,635 Da (Fig. 1), a purity of $96.89 \%$ and a polysaccharide to peptide ratio of 88.70:11.30\%. HILIC-ELSD data indicated that polysaccharides were primarily composed of 1-arabinose, d-mannose and d-glucose at a molar ratio of 1.329:0.372:2.953 (Fig. 2).
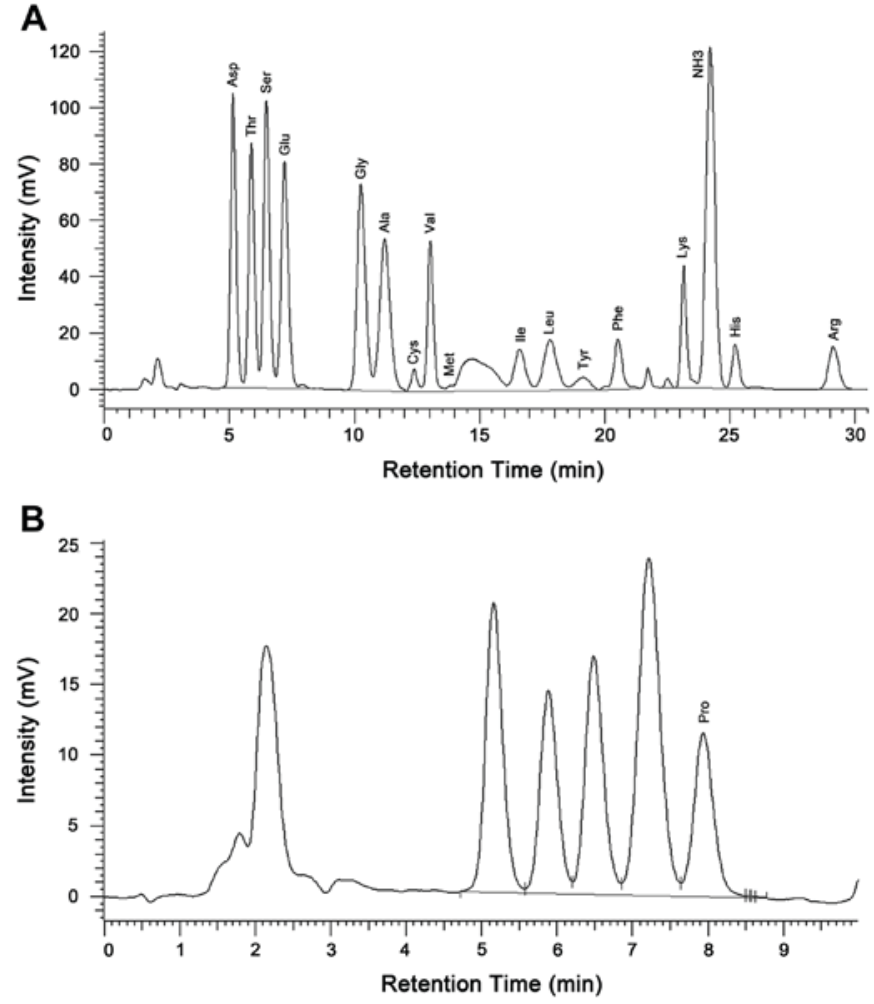

Figure 3. The fingerprint amino acid composition spectrum of GL-PP. (A) Amino acid composition spectrum in channel 1. (B) Amino acid composition spectrum in channel 2.

The amino acid automatic analyzer indicated that the peptide contained 17 amino acids, including Asp, Thr, Ser, Glu, Gly, Ala, Cys, Val, Met, Ile, Leu, Tyr, Phe, Lys, His, Arg and Pro, with a respective mass ratio of: 1.45:1.08:1.12:1.45:0.84:0.87:0.19:0.64: 0.01:0.38:0.56:0.23:0.47:0.58:0.30:0.53:0.60 (Table I and Fig. 3). No detectable level of endotoxin $(\leq 0.10 \mathrm{EU} / \mathrm{ml})$ was identified in the GL-PP samples.

GL-PP inhibits the proliferation of U251 cells. Cells were incubated with varying concentrations of GL-PP (50, 100, 200, 400 and $800 \mu \mathrm{g} / \mathrm{ml}$ ) for 24,48 or $72 \mathrm{~h}$. GL-PP markedly inhibited the proliferation of $\mathrm{U} 251$ cells in a dose-dependent manner compared with untreated controls. The maximum inhibition observed at $48 \mathrm{~h}$ among all treatment groups except $400 \mu \mathrm{g} / \mathrm{ml}$ group (Fig. 4). The half-maximal inhibitory concentration of GL-PP at $48 \mathrm{~h}$ was $274.1 \mu \mathrm{g} / \mathrm{ml}$.

GL-PP blocks cell cycle progression at the $G_{0} / G_{I}$ phase and induces apoptosis. To examine how GL-PP inhibited cell proliferation and viability, flow cytometry was utilized to determine the effect of GL-PP on cell cycle progression. Results revealed that the presence of G0/G1 phase cells was increased from 62.9 to $74.94 \%$ at $48 \mathrm{~h}$ with increasing concentrations of GL-PP among all groups. This increase was accompanied by a significant decrease in the percentage of $\mathrm{S}$ phase cells, whereas the fraction of $\mathrm{G}_{2} / \mathrm{M}$ phase cells was primarily unchanged. The sub- $\mathrm{G}_{1}$ phase cell population, which indicate the number of late-stage apoptotic cells, also increased significantly in GL-PP treated cells in a dose-dependent manner (Fig. 5). This result demonstrated that GL-PP induced $G_{0} / G_{1}$ phase arrest and apoptosis induction. 
Table I. Amino acid comparisons of Ganoderma lucidum polysaccharide peptide.

\begin{tabular}{lcc}
\hline Amino acid & Category & Contents (\%) \\
\hline Asparagine & $\mathrm{N}$ & 1.45 \\
Threonine & $\mathrm{N}$ & 1.08 \\
Serine & $\mathrm{N}$ & 1.12 \\
Glutamic acid & $\mathrm{N}$ & 1.45 \\
Glycine & $\mathrm{N}$ & 0.84 \\
Alanine & $\mathrm{N}$ & 0.87 \\
Cystine & $\mathrm{N}$ & 0.19 \\
Valine & $\mathrm{E}$ & 0.64 \\
Methionine & $\mathrm{E}$ & 0.01 \\
Isoleucine & $\mathrm{E}$ & 0.38 \\
Leucine & $\mathrm{E}$ & 0.56 \\
Tyrosine & $\mathrm{N}$ & 0.23 \\
Phenylalanine & $\mathrm{E}$ & 0.47 \\
Lysine & $\mathrm{E}$ & 0.58 \\
Histidine & $\mathrm{N}$ & 0.30 \\
Arginine & $\mathrm{N}$ & 0.53 \\
Proline & $\mathrm{N}$ & 0.60 \\
Total & - & 11.3 \\
\hline
\end{tabular}

E, essential; N, non-essential.

GL-PP induces apoptosis specific caspase-3 activity in U251 cells. To examine the induction of apoptosis by GL-PP, the activation of caspase-3, a primary enzyme in cell apoptosis, was assessed. The expression of active caspase- 3 in GL-PP-treated U251 cells was determined using western blotting. The active caspase- 3 level was increased in a dose-dependent manner following treatment with 50, 100, 200,400 or $800 \mu \mathrm{g} / \mathrm{ml} \mathrm{GL}-\mathrm{PP}$ for $48 \mathrm{~h}$ (Fig. 6). In addition, the activation of caspase- 3 was analyzed by measuring the catalytic capability to the substrate Ac-DEVD-pNA. The result showed the activation of caspase-3 significantly increased in GL-PP treated groups in a dose-dependent manner (Fig. 7). This agrees with the result obtained by western blot analysis (Fig. 6).

\section{Discussion}

GL-PS and G. lucidum glycopeptides have been identified as potential natural sources of anticancer compounds (38). The present study identified, purified and tested the anti-glioma activity of a novel glycopeptide from grass-cultured G. lucidum, GL-PP, in vitro. GL-PP strongly inhibited human U251 glioma cell proliferation in a dose-dependent manner through cell cycle arrest and induction of apoptosis.

The sustainment of proliferative signaling and the resistance to apoptosis are two hallmarks of cancer (39). In the present study, human U251 glioma cells treated with GL-PP, exhibited $\mathrm{G}_{0} / \mathrm{G}_{1}$ cell cycle arrest and inhibited proliferation. Furthermore, the proportion of hypoploid cells $\left(\mathrm{sub}-\mathrm{G}_{1}\right)$ and the activity of caspase- 3 markedly increased, indicating that GL-PP induced U251 glioma cell apoptosis.
A

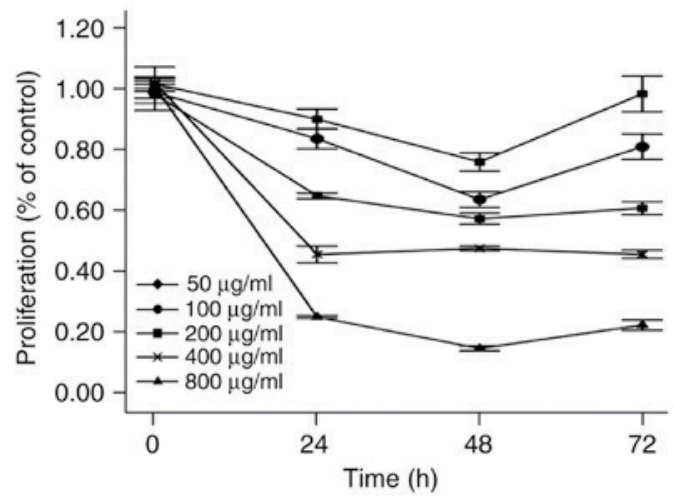

B
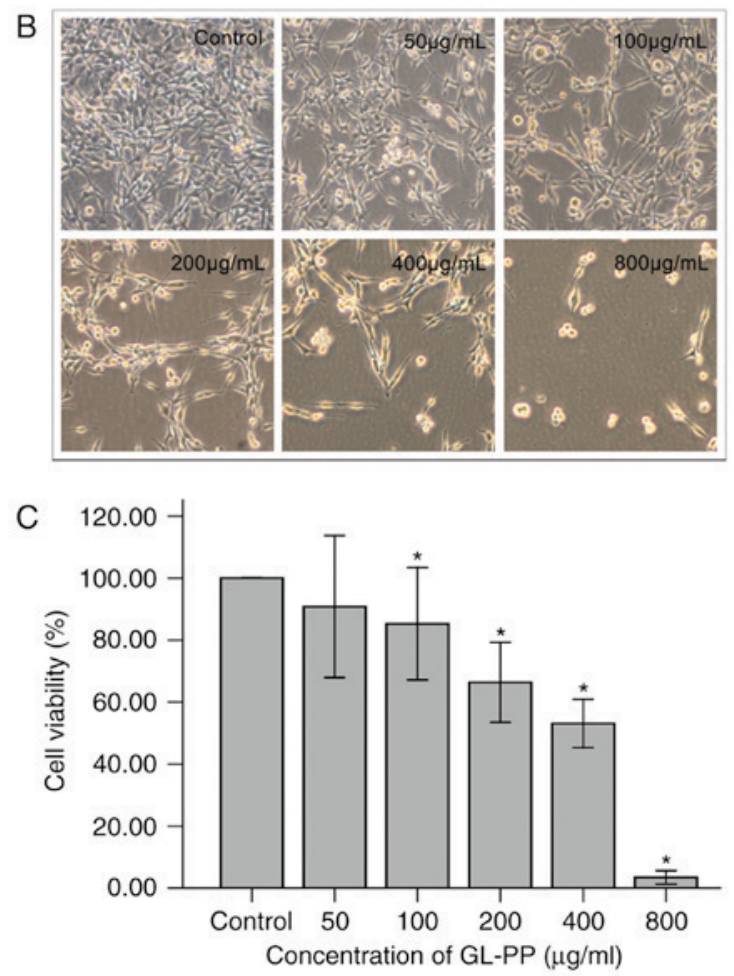

Figure 4. Effect of GL-PP on the proliferation and viability of U251 glioma cells. (A) The proliferation of U251 cells was markedly inhibited by GL-PP in a dose-dependent manner compared with controls. (B) U251 cells in culture under light microscope (magnification, x100) following treatment with GL-PP for 48 h. (C) Cell viability was examined $48 \mathrm{~h}$ after treatment with GL-PP using a Cell Counting Kit-8 assay. Except the $50 \mu \mathrm{g} / \mathrm{ml}$ GL-PP group, the ratio of cell viability in all GL-PP treated groups was significantly lower than control group. Data are presented as the mean \pm standard deviation, "P $<0.05$ vs. control. GL-PP, Ganoderma lucidum polysaccharide peptide.

Although the antitumor activity of GL-PS/GL-PP has been demonstrated in previous studies $(8,10,14,38,40,41)$, whether GL-PS/GL-PP directly inhibits cancer cell proliferation or induces cellular apoptosis remains unknown. A study by Cao et al (31) indicated that GL-PP inhibited human lung carcinoma cell migration in a dose-dependent manner by inhibiting the expression and activity of matrix metalloproteinase-9. However, no inhibitory effect on cellular proliferation was identified. Li et al (42) also demonstrated that GL-PS had no cytotoxic effect on human prostate carcinoma PC-3M cells. In addition, a study by Oliveira et al (32) revealed that polysaccharide extracts from G. lucidum exhibited no cytotoxic activity, as all tumor cell lines (AGS, MCF-7, NCI-H460 and HCT-15) exhibited a concentration causing a $50 \%$ reduction in proliferation $>400 \mu \mathrm{g} / \mathrm{ml}$. 

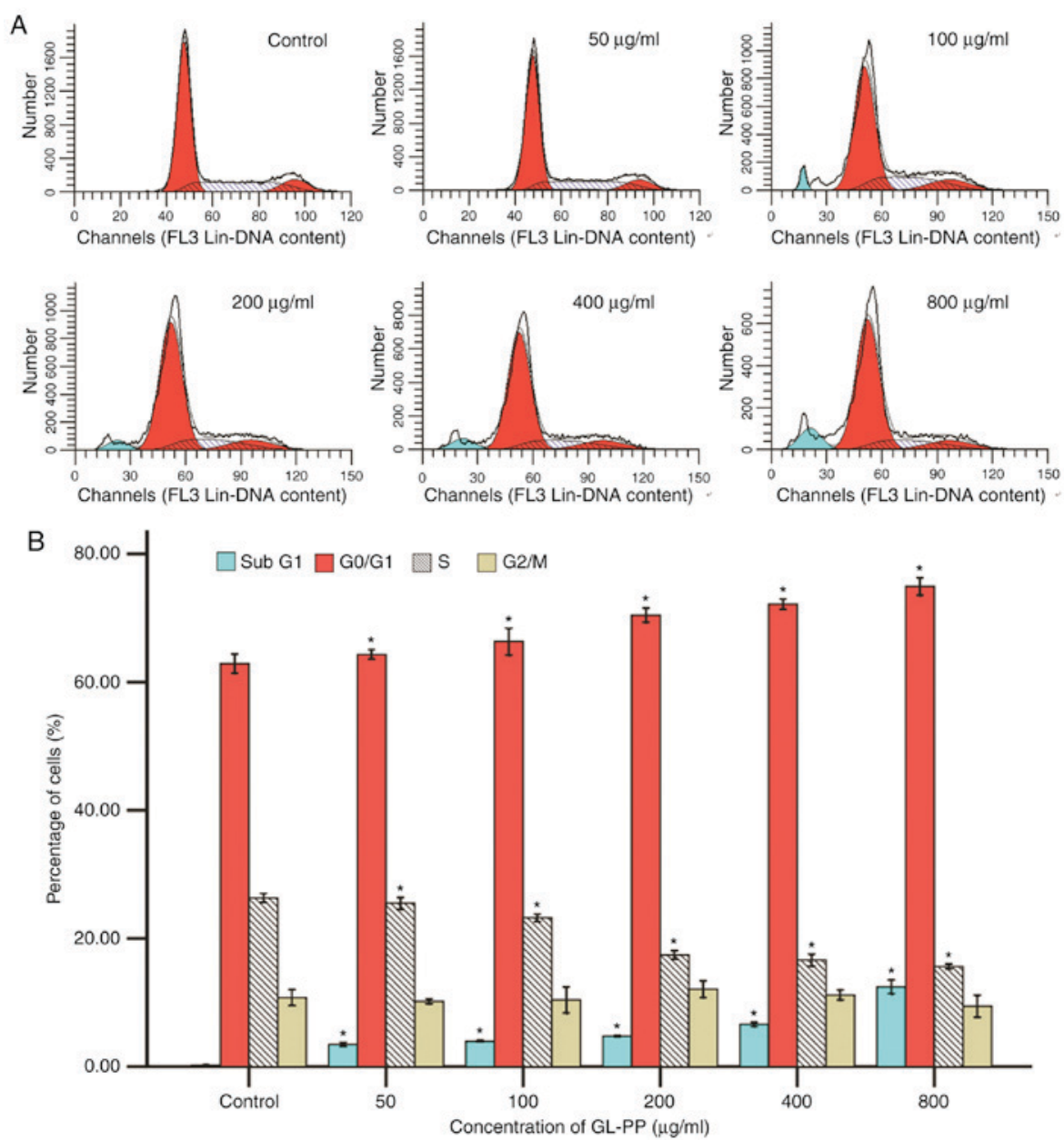

Figure 5. Cell cycle distribution of U251 cells exposed to different concentrations of GL-PP. (A) Cells were incubated with GL-PP for $48 \mathrm{~h}$ and the percentage of cells in each cell cycle phase was determined using flow cytometry. (B) Cell cycle distribution of different treatment groups. The population of cells in the sub- $\mathrm{G}_{1}$ phase consisted of cellular fragments resulting from apoptosis. Data are presented as the mean \pm standard deviation. ${ }^{*} \mathrm{P}<0.05$ vs. control. GL-PP, Ganoderma lucidum polysaccharide peptide.
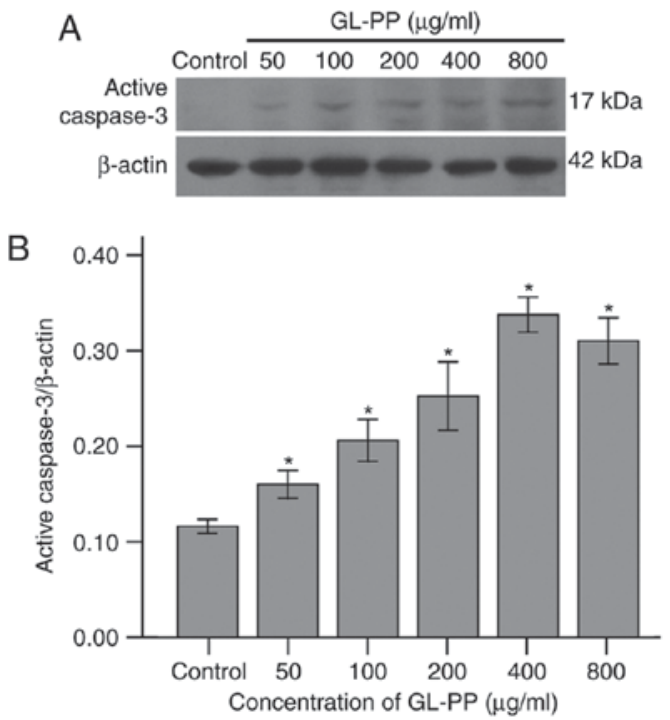

Figure 6. Effect of GL-PP on the expression of active caspase-3 in U251 cells (A) Caspase-3 expression in U251 cells was detected by western blotting $48 \mathrm{~h}$ after treatment with the indicated concentrations of GL-PP. (B) The expression of active caspase- 3 presented was calculated from three independent experiments. Each value was expressed as the ratio of active caspase- 3 to $\beta$-actin. Data are presented as the mean \pm standard deviation, ${ }^{*} \mathrm{P}<0.01$ vs. control. GL-PP, Ganoderma lucidum polysaccharide peptide.

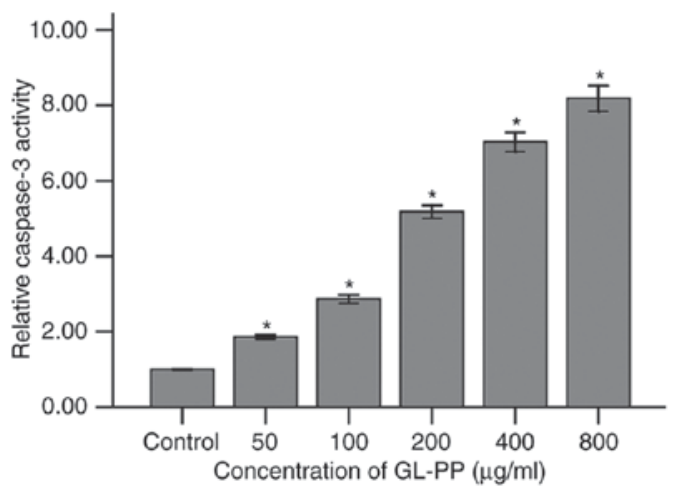

Figure 7. Relative caspase-3 activity detected using a colorimetric assay. Data presented was calculated from three independent experiments. Each value was expressed as the ratio of the caspase- 3 activation level to the control level; the value of the control was set to 1 . Data are presented as the mean \pm standard deviation, ${ }^{*} \mathrm{P}<0.01$ vs. control. GL-PP, Ganoderma lucidum polysaccharide peptide.

However, other studies have demonstrated that GL-PS/GL-PP significantly inhibited the proliferation of certain types of cancer cell in vitro, including breast cancer (14), ovarian cancer (15), hepatoma (11) and colorectal adenocarcinoma cells (11). The 
findings of the present study are similar to these results, but concern glioma cells.

The apparent discrepancies of previous studies on the anti-proliferative effects of GL-PS/GL-PP may be due to the variability in the chemical constituents of GL-PS/GL-PP and the different origins of the cancer cell lines utilized. It has been determined that the biological activities of polysaccharides are associated with their chemical conformation, molecular weight, chemical modification and content of bound protein (43-46). For example, the native triple-helix conformation with $\beta-(1-3)$ linkages in the primary glucan chain and additional $\beta$-(1-6) branch points of polysaccharides are considered to be necessary for antitumor activity (47). Furthermore, analysis performed by Yeh et al (9) compared de-proteinized polysaccharides with ling zhi-8 (LZ-8) and determined that LZ- 8 activates murine macrophages and T lymphocytes, but a de-proteinized polysaccharide only acts as a macrophage activator, indicating that retaining proteins and the natural complex of polysaccharides may serve a vital role in the biological activities that they exhibit.

The GL-PP used in the present study was isolated from G. lucidum and cultivated with JUNCAO grasses. According to a previous study (48), the glycopeptides obtained from grass-cultured G. lucidum (GLPG) have a similar molecular weight, monosaccharide constituent and amino acid composition to those obtained from wood-log-cultured G. lucidum (GLPW), which are each primarily attached by $\beta$-glycosidic linkages. GLPG has a higher purification rate $(2.8$ times that of GLPW) and is more environmentally friendly than GLPW, which relies on a large consumption of forest resources. Compared with previous studies $(15,17,26)$, the GL-PP extract utilized in the present study has a smaller molecular weight $(42,635 \mathrm{kDa})$, contained fewer monosaccharides and exhibited a higher proportion of peptide (11.3\%). Only glucose, mannose and arabinose were detected in the GL-PP isolated in the current study. The other monosaccharides often present in GL-PS/GL-PP extracts, including galactose, rhamnose, fucose, xylose $(15,17,26)$, were not detected. In addition, 17 different amino acids were detected in the GL-PP extract utilized in the present study, including tyrosine, which has not been detected in GL-PS/GL-PP in previous studies. These differences may be partly due to the different isolation procedures and detection methods used, and may ultimately serve a role in the unique biological activities identified in the present study.

Although the present study determined the molecular weight, and monosaccharide and amino acid composition of GL-PP, to clearly ascribe the anti-proliferative effects to its chemical structure, a more thorough characterization is required. Elucidation of the molecular mechanisms and signaling pathways involved in GL-PP anti-glioma activity should also be performed in future studies. Additionally, although the direct anti-glioma activity of GL-PP has been observed in vitro, it may be limited by a number of elements in vivo, including biotransformation and the blood-brain barrier. Addressing these limitations may clarify the immunomodulatory activities of GL-PP and its inhibitory role in glioma growth in vivo.

In conclusion, the present study demonstrated that the GL-PP isolated from the G. lucidum cultivated with Juncao grasses demonstrates a potent inhibitive capacity on human
U251 glioma cell lines. The demonstrated in vitro anti-glioma activity of GL-PP was determined to be dose-dependent, and mediated by cell cycle arrest and induction of apoptosis. Therefore, GL-PP may represent a natural addition to the treatment regimen of patients with glioma.

\section{Acknowledgements}

The present study was supported by the China National Engineering Research Center of JUNCAO Technology (grant no. JCJJ14008). The authors would like to thank Saizhen Wang, the Senior Engineer from the Fuzhou Institute of Green Valley Bio-Pharm Technology, for her technical assistance in the preparation of GL-PP. The authors would also like to thank the Central Laboratory of Fujian Academy of Agricultural Science for performing amino acid analyses.

\section{References}

1. Omuro A and DeAngelis LM: Glioblastoma and other malignant gliomas: A clinical review. JAMA 310: 1842-1850, 2013.

2. Van Meir EG, Hadjipanayis CG, Norden AD, Shu HK, Wen PY and Olson JJ: Exciting new advances in neuro-oncology: The avenue to a cure for malignant glioma. CA Cancer J Clin 60: 166-193, 2010.

3. Song YH, Sun H, Zhang AH, Yan GL, Han Y and Wang XJ: Plant-derived natural products as leads to anti-cancer drugs. J Med plant Herbal Ther Res 2: 6-15, 2014.

4. Habijanic J, Berovic M, Boh B, Plank1 M. and Wraber B: Submerged cultivation of Ganoderma lucidum and the effects of its polysaccharides on the production of human cytokines TNF- $\alpha$, IL-12, IFN- $\gamma$, IL-2, IL-4, IL-10 and IL-17. N Biotechnol 32: 85-95, 2015.

5. Lai CY, Hung JT, Lin HH, Yu AL, Chen SH, Tsai YC, Shao LE, Yang WB and Yu J: Immunomodulatory and adjuvant activities of a polysaccharide extract of Ganoderma lucidum in vivo and in vitro. Vaccine 28: 4945-4954, 2010.

6. Meng J, Hu X, Shan F, Hua H, Lu C, Wang E and Liang Z: Analysis of maturation of murine dendritic cells (DCs) induced by purified Ganoderma lucidum polysaccharides (GLPs). Int J Biol Macromol 49: 693-699, 2011.

7. Shi Y, Cai D, Wang X and Liu X: Immunomodulatory effect of Ganoderma lucidum polysaccharides (GLP) on long-term heavy-load exercising mice. Int J Vitam Nutr Res 82: 383-390, 2012.

8. Xu Z, Chen X,Zhong Z, Chen L and Wang Y: Ganoderma lucidum polysaccharides: Immunomodulation and potential anti-tumor activities. Am J Chin Med 39: 15-27, 2011.

9. Yeh CH, Chen HC, Yang JJ, Chuang WI and Sheu F: Polysaccharides PS-G and protein LZ-8 from Reishi (Ganoderma lucidum) exhibit diverse functions in regulating murine macrophages and T lymphocytes. J Agric Food Chem 58: 8535-8544, 2010

10. Zhang S, Nie S, Huang D, Feng Y and Xie M: A novel polysaccharide from Ganoderma atrum exerts antitumor activity by activating mitochondria-mediated apoptotic pathway and boosting the immune system. J Agric Food Chem 62: 1581-1589, 2014.

11. Gao Y, Gao H, Chan E, Tang W, Xu A, Yang H, Huang M, Lan J, Li X, Duan W, et al: Antitumor activity and underlying mechanisms of ganopoly, the refined polysaccharides extracted from Ganoderma lucidum, in mice. Immunol Invest 34: 171-198, 2005.

12. Joseph S, Sabulal B, George V, Antony KR and Janardhanan KK: Antitumor and anti-inflammatory activities of polysaccharides isolated from Ganoderma lucidum. Acta Pharm 61: 335-342, 2011.

13. Liang CJ, Lee CW, Sung HC, Chen YH, Chiang YC, Hsu HY, Tseng YC, Li CY, Wang SH and Chen YL: Ganoderma lucidum polysaccharides reduce lipopolysaccharide-induced interleukin- $1 \beta$ expression in cultured smooth muscle cells and in thoracic aortas in mice. Evid Based Complement Alternat Med 2014: 305149, 2014. 
14. Shang D, Li Y, Wang C, Wang X, Yu Z and Fu X: A novel polysaccharide from Se-enriched Ganoderma lucidum induces apoptosis of human breast cancer cells. Oncol Rep 25: 267-272, 2011.

15. Shang D, Zhang J, Wen L, Li Y and Cui Q: Preparation, characterization, and antiproliferative activities of the Se-containing polysaccharide SeGLP-2B-1 from Se-enriched Ganoderma lucidum. J Agric Food Chem 57: 7737-7742, 2009.

16. Wang J, Zhang L, Yu Y and Cheung PC: Enhancement of antitumor activities in sulfated and carboxymethylated polysaccharides of Ganoderma lucidum. J Agric Food Chem 57: 10565-10572, 2009.

17. Cao QZ and Lin ZB: Antitumor and anti-angiogenic activity of Ganoderma lucidum polysaccharides peptide. Acta Pharmacol Sin 25: 833-838, 2004.

18. Cao QZ and Lin ZB: Ganoderma lucidum polysaccharides peptide inhibits the growth of vascular endothelial cell and the induction of VEGF in human lung cancer cell. Life Sci 78: 1457-1463, 2006

19. Kan Y, Chen T, Wu Y, Wu J and Wu J: Antioxidant activity of polysaccharide extracted from Ganoderma lucidum using response surface methodology. Int J Biol Macromol 72: 151-157, 2015.

20. Liu W, Wang H, Pang X, Yao W and Gao X: Characterization and antioxidant activity of two low-molecular-weight polysaccharides purified from the fruiting bodies of Ganoderma lucidum. Int J Biol Macromol 46: 451-457, 2010.

21. Yang Q, Wang S, Xie Y, Sun J and Wang J: HPLC analysis of Ganoderma lucidum polysaccharides and its effect on antioxidant enzymes activity and Bax, Bcl-2 expression. Int J Biol Macromol 46: 167-172, 2010.

22. Zhao W, Jiang X, Deng W, Lai Y, Wu M and Zhang Z: Antioxidant activities of Ganoderma lucidum polysaccharides and their role on DNA damage in mice induced by cobalt- 60 gamma-irradiation. Food Chem Toxicol 50: 303-309, 2012

23. Liang Z, Yi Y, Guo Y, Wang R, Hu Q and Xiong X: Chemical characterization and antitumor activities of polysaccharide extracted from Ganoderma lucidum. Int J Mol Sci 15: 9103-9116, 2014.

24. Chang SS, Zhou D, Meng GL, Wu F, Wang S, Chen X and Xu JL: Effect of Ganoderma lucidum polysaccharides on oxidative stress of hyperlipidemic fatty liver in rats. Zhongguo Zhong Yao Za Zhi 37: 3102-3106, 2012 (In Chinese).

25. Zhang GL, Wang YH, Ni W, Teng HL and Lin ZB: Hepatoprotective role of Ganoderma lucidum polysaccharide against BCG-induced immune liver injury in mice. World J Gastroenterol 8: 728-733, 2002.

26. Sun LX, Lin ZB, Duan XS, Lu J, Ge ZH, Li XJ, Li M, Xing EH, Jia J, Lan TF and Li WD: Ganoderma lucidum polysaccharides antagonize the suppression on lymphocytes induced by culture supernatants of B16F10 melanoma cells. J Pharm Pharmacol 63: 725-735, 2011

27. Sun LX, Lin ZB, Li XJ, Li M, Lu J, Duan XS, Ge ZH, Song YX, Xing EH and Li WD: Promoting effects of Ganoderma lucidum polysaccharides on $\mathrm{B} 16 \mathrm{~F} 10$ cells to activate lymphocytes. Basic Clin Pharmacol Toxicol 108: 149-154, 2011.

28. Zhang P, Ding R, Jiang S, Ji L, Pan M, Liu L, Zhang W, Gao X, Huang W, Zhang G, et al: The adjuvanticity of Ganoderma lucidum polysaccharide for Newcastle disease vaccine. Int J Biol Macromol 65: 431-435, 2014.

29. Zhu XL, Chen AF and Lin ZB: Ganoderma lucidum polysaccharides enhance the function of immunological effector cells in immunosuppressed mice. J Ethnopharmacol 111: 219-226, 2007.

30. Zheng S, Jia Y, Zhao J, Wei Q and Liu Y: Ganoderma lucidum polysaccharides eradicates the blocking effect of fibrinogen on NK cytotoxicity against melanoma cells. Oncol Lett 3: 613-616, 2012.

31. Cao QZ, Lin SQ and Wang SZ: Effect of Ganoderma lucidum polysaccharides peptide on invasion of human lung carcinoma cells in vitro. Beijing Da Xue Xue Bao Yi Xue Ban 39: 653-656, 2007 (In Chinese).
32. Oliveira M, Reis FS, Sousa D, Tavares C, Lima RT, Ferreira IC, dos Santos T and Vasconcelos MH: A methanolic extract of Ganoderma lucidum fruiting body inhibits the growth of a gastric cancer cell line and affects cellular autophagy and cell cycle. Food Funct 5: 1389-1394, 2014

33. Sun LX, Lin ZB, Duan XS, Lu J, Ge ZH, Li M, Xing EH, Lan TF, Jiang MM, Yang N and Li WD: Ganoderma lucidum polysaccharides counteract inhibition on CD71 and FasL expression by culture supernatant of B16F10 cells upon lymphocyte activation. Exp Ther Med 5: 1117-1122, 2013.

34. Wang PY,Zhu XL and Lin ZB: Antitumor and immunomodulatory effects of polysaccharides from broken-spore of Ganoderma lucidum. Front Pharmacol 3: 135, 2012.

35. Sun LX, Chen LH, Lin ZB, Qin Y, Zhang JQ, Yang J, Ma J, Ye T and Li WD: Effects of Ganoderma lucidum polysaccharides on IEC- 6 cell proliferation, migration and morphology of differentiation benefiting intestinal epithelium healing in vitro. J Pharm Pharmacol 63: 1595-1603, 2011.

36. Wang SZ, Lin ZX, Lin DM, Lin SQ, Lin ZB and Li J: Structure of polysaccharide peptide GL-PPS from Ganoderma lucidum. Southwest China J Agricultural Sci 28: 793-796, 2015.

37. Gong Y, Huang Y, Gao L, Lu J, Hu Y, Xia L and Huang H: Chinese standard GB/T 5009.124-2003. Inspection of grain and oilseeds: Method for determination of amino acids in foods. Standards press of China, Beijing, China, 2003. J Food Nut Res 1: 108-112, 2013.

38. Boh B: Ganoderma lucidum: A potential for biotechnological production of anti-cancer and immunomodulatory drugs. Recent Pat Anticancer Drug Discov 8: 255-287, 2013.

39. Hanahan D and Weinberg RA: Hallmarks of cancer: The next generation. Cell 144: 646-674, 2011.

40. Liu YJ, Shen J, Xia YM,Zhang J and Park HS: The polysaccharides from Ganoderma lucidum: Are they always inhibitors on human hepatocarcinoma cells? Carbohydr Polym 90: 1210-1215, 2012.

41. Shen J, Park HS, Xia YM, Kim GS and Cui SW: The polysaccharides from fermented Ganoderma lucidum mycelia induced miRNAs regulation in suppressed HepG2 cells. Carbohydr Polym 103: 319-324, 2014.

42. Li YB, Li YH, Wang R, Lin ZB and Li ZJ: Efect of Ganoderma lucidumpolysaccharides (GIPS) on tumor-endothelium interactions. Chin Pharmacol Bull 39: 250-253, 2008.

43. Chen X, Xu X, Zhang L and Zeng F: Chain conformation and anti-tumor activities of phosphorylated $(1 \rightarrow 3)-\beta$-d-glucan from Poria cocos. Carbohydr Polymers 78: 581-587, 2009.

44. Surenjav U, Zhang L, Xu X, Zhang X and Zeng F: Effects of molecular structure on antitumor activities of $(1 \rightarrow 3)$ - $\beta$-d-glucans from different Lentinus Edodes. Carbohydr Polymers 63: 97-104, 2006.

45. Wang Y, Zhang L, Li Y, Hou X and Zeng F: Correlation of structure to antitumor activities of five derivatives of a beta-glucan from Poria cocos sclerotium. Carbohydr Res 339: 2567-2574, 2004.

46. Zhang L, Li X, Xu X and Zeng F: Correlation between antitumor activity, molecular weight, and conformation of lentinan. Carbohydr Res 340: 1515-1521, 2005.

47. Wasser SP: Medicinal mushrooms as a source of antitumor and immunomodulating polysaccharides. Appl Microbiol Biotechnol 60: 258-274, 2002.

48. Lin SQ, Wang SZ, Lin ZB and Lin YX: Isolation and identification of active components of Ganoderma lucidum cultivated with grassand wood log I. Extraction, purification and characterization of glycopeptide. Chin Tradit Herbal Drugs 34: 872-874, 2003.

(i) $\odot$ This work is licensed under a Creative Commons Attribution-NonCommercial-NoDerivatives 4.0 International (CC BY-NC-ND 4.0) License. 